\title{
Os sentidos da palavra "linguagem" na Gramática do Português Contemporâneo de Celso Cunha e Lindley Cintra: uma análise enunciativa
}

\author{
The meaning of the word "language" in the Gramática do Português \\ Contemporâneo by Celso Cunha and Lindley Cintra: an enunciative analysis
}

\author{
Rossana Oliveira Reis ${ }^{1}$ \\ Universidade Estadual do Sudoeste da Bahia \\ Priscila Taylana Carvalho de Souza ${ }^{2}$ \\ Universidade Estadual do Sudoeste da Bahia \\ Adilson Ventura ${ }^{3}$ \\ Universidade Estadual do Sudoeste da Bahia
}

\begin{abstract}
- RESUMO: No presente artigo apresentamos os resultados da análise dos sentidos da palavra "linguagem" nos dois capítulos iniciais da Gramática do Português Contemporâneo de Celso Cunha e Lindley Cintra (1998). Segundo a linha teórica que adotamos, a Semântica do Acontecimento, o sentido é constituído linguisticamente, ou seja, a significação é construída pelas relações de linguagem. E importa, para se observar estas relações de linguagem, compreender a temporalidade em que elas ocorrem. Assim, temos que a enunciação, ou acontecimento do dizer, é que estabelece esta temporalidade, na medida em que recorta um memorável (uma enunciação passada) e produz uma futuridade (latência de futuro), uma vez que, é nessa latência de futuro que se encontram as possibilidades de sentido. O que fizemos, então, foi uma análise enunciativa do corpus em questão, considerando que, para Guimarães (2009): "O sentido é produzido pelo acontecimento da enunciação", sendo que a enunciação é considerada como o momento no qual o Locutor, através das realizações enunciativas, entra em contato com aquilo que ele fala. O estudo foi feito observando os procedimentos enunciativos de reescrituração e articulação dentro do texto, para que pudéssemos assim construir o seu DSD (Domínio Semântico de Determinação), que, de acordo com Eduardo Guimarães (2007), apresenta o funcionamento do sentido de uma palavra na enunciação. Este nosso trabalho insere-se em um projeto de pesquisa que vem sendo desenvolvido na Universidade Estadual do Sudoeste da Bahia, projeto esse que busca compreender os sentidos da palavra interpretação em materiais utilizados para ensino no Brasil.
\end{abstract}

- PALAVRAS-CHAVE: Gramática; Linguagem; Semântica do acontecimento; Sentidos

- ABSTRACT: In the present article we present the results of the analysis of the meanings of the word "language" in the first two chapters of the Gramática do Português Contemporâneo of Celso Cunha and Lindley Cintra (1998). According to the theoretical line that we adopt, the Semântica do acontecimento, the meaning is constituted linguistically, that is, the meaning is constructed by the relations of language. It is important, in order to observe these relations of language, to understand the temporality in which they occur. Thus we have the utterance, or event of saying, it is establishing this temporality, in that it cuts

\footnotetext{
${ }^{1}$ Graduação em andamento no curso de Letras Modernas, na Universidade Estadual do Sudoeste da Bahia - UESB. Bolsista em iniciação científica pela Fundação de Amparo à pesquisa do Estado da Bahia - FAPESB. rossana.reis.oliveira@gmail.com

${ }^{2}$ Graduação em andamento no curso de Letras Modernas na Universidade Estadual do Sudoeste da Bahia - UESB. Bolsista em Iniciação Científica pelo CNPq. pris.carvalho24@gmail.com

${ }^{3}$ Doutor em Linguística pela UNICAMP. Professor Adjunto do Departamento de Estudos Linguísticos e Literários DELL - da Universidade Estadual do Sudoeste da Bahia - UESB. Professor do Programa de Pós-Graduação em Linguística - PPGLin/ UESB. Professor do Mestrado Profissional em Letras - PROFLETRAS. adilson.ventura@gmail.com
} 
one memorable (a past utterance) and produces a futurity (future latency), since it is in this future latency are the possibilities of meaning. What we did then was a corpus enunciation analysis in question, whereas, in Guimarães (2009): "O sentido é produzido pelo acontecimento da enunciação", and the utterance is considered as the moment in which the announcer through of enunciative realizations, comes into contact with what he speaks. The study was conducted in compliance with the enunciation procedures reescrituração and articulação within the text, we could thus build their DSD (Domínio Semântico de Determinação), which, according to Eduardo Guimaraes (2007) presents the operation of the meaning of a word in the enunciation. This work is part of a research project that has been developed at the Universidade Estadual do Sudoeste da Bahia, a project that seeks to understand the meanings of the word interpretation in materials used for teaching in Brazil.

- KEYWORDS: Grammar; Language; Meaning; Semântica do Acontecimento

\section{Introdução}

O trabalho que empreendemos é resultado de análises que têm como fim entender a construção do sentido de palavras que influenciam o processo de interpretação. Entendemos que as concepções da palavra linguagem, apresentadas em materiais didáticos, contribuem para a compreensão de textos, pois o que se entende por linguagem interfere na relação dos leitores com a interpretação textual. Pensando na relevância desses estudos, analisamos os sentidos da palavra linguagem presente nos dois capítulos iniciais da Gramática do Português contemporâneo de Celso Cunha e Lindley Cintra (1998). Com esse artigo contribuímos com um trabalho maior que vem sendo desenvolvido na Universidade Estadual do Sudoeste da Bahia, que procura compreender os sentidos da palavra interpretação presentes nos materiais utilizados para ensino no Brasil, e, assim, entender o que se entende por interpretação nesses materiais.

Para tal análise, nos posicionamos a partir da Semântica do Acontecimento, teoria proposta por Eduardo Guimarães, e que tem como base os estudos da enunciação propostos por Benveniste, pelos estudos da argumentação, propostos por Ducrot, além de um diálogo decisivo com a Análise de Discurso. A partir da teoria de Guimarães é que pudemos empreender a análise dos sentidos produzidos em um texto a partir dos procedimentos enunciativos da reescrituração e articulação. O nosso objetivo era conseguir compreender a construção dos sentidos da palavra linguagem no referido material, buscando observar as suas reescrituras e articulações no texto. Com base na teoria desenvolvida por Guimarães é que construímos o DSD (Domínio Semântico de Determinação) para apresentar as relações de significação que ocorrem no seguinte texto.

\section{A semântica do acontecimento}

Segundo Guimarães (2002), o sentido do enunciado se dá no momento da enunciação, ou seja, no momento no qual há a relação entre o locutor e a língua e, por conta disso, uma enunciação é sempre distinta da anterior. Porém, a enunciação não é dependente somente do sujeito no momento em que fala, ela está funcionando historicamente, ou seja, ao ser enunciada ela recorta um memorável e cria uma futuridade. O sentido não é construído porque referencia algo, ele é resultado de uma ação enunciativa, na qual o sentido é produzido por uma relação da linguagem com ela mesma. "[...] São as relações enunciativas do acontecimento que constituem sentido

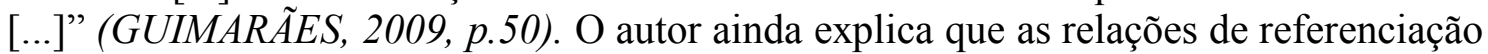


são importantes para a semântica, porém, esse fenômeno ocorre em uma esfera extralinguística que corrobora com a construção de linguagem.

A enunciação opera "Por uma relação do locutor com aquilo que ele fala, do locutor com o acontecimento no qual ele fala aquilo que ele fala [...] por uma relação entre os elementos linguísticos." (GUIMARÃES, 2009, p.50). Contudo, a enunciação não ocorre no tempo cronológico no qual costumamos pensar, ela possui a sua própria temporalidade, e esta funciona a partir do acontecimento do dizer. No momento em que algo é enunciado, faz-se um recorte de um memorável no passado - em que o memorável é algo que possui sentido dentro de uma comunidade linguística e já foi dito anteriormente - e abre uma latência para o futuro, ou seja, cria possibilidades de interpretação. Ainda sobre a temporalidade da enunciação, Guimarães explica que a temporalidade não tem origem no sujeito no momento em que ele fala algo, mas que é o próprio acontecimento do dizer quem cria a sua temporalidade.

Contudo, após compreendermos a temporalidade enunciativa, é necessário observar qual o lugar onde se dá as enunciações. Guimarães explica que a enunciação ocorre dentro de um espaço político e em cenas enunciativas - ao passo que ele define como espaço político o lugar de disputa da palavra - . A cena enunciativa é o recorte no espaço da enunciação no qual " [....] Uma cena enunciativa caracteriza por constituir modos específicos de acesso à palavra, dadas as relações entre as figuras da enunciação e as formas linguísticas." (GUIMARÃES, 2002, p.23). Ou seja, as cenas enunciativas agenciam o lugar social de onde o Locutor diz algo.

O que Guimarães chamou de Locutor - ou L- foi esse Locutor, que não é o sujeito real, mas a fonte do dizer, e, como fonte, cabe a ele marcar o presente do acontecimento enunciativo. Entretanto, Guimarães explica que, para que o Locutor represente a origem do dizer, é necessário que ele esteja alocado em um lugar social que o permita dizer algo. Ao exemplo do locutor-presidente que pode decretar uma lei, por razão do lugar social de presidente que ele ocupa, ao passo que ao locutor-secretário não é permitido realizar a mesma ação enunciativa.

\section{Procedimentos enunciativos}

Para compreender como se dão os sentidos, Guimarães propõe analisarmos os procedimentos de agenciamento enunciativos que funcionam dentro de um texto, são eles: a reescritura e a articulação. Portanto, será através desses dois mecanismos que apresentaremos o processo de significação e os sentidos que foram produzidos no corpus de nossa análise.

Para explicar o processo de reescritura - que é um dos procedimentos de análise que nos permite estudar a atribuição de sentido à palavra -, Guimarães $(2007$, p. 84) diz que "A reescrituração é o procedimento pelo qual a enunciação de um texto rediz insistentemente o que já foi dito fazendo interpretar uma forma como diferente de si.", ou seja, no processo de reescrituração a palavra é ressignificada toda vez em que esta for reescrita no texto. O linguista complementa informando que o processo de reescrituração acaba por criar a predicação, e esta seria importante no ponto em que trata das ligações que são feitas no texto e que acabam produzindo os sentidos. A reescritura pode aparecer em um texto por: expansão, condensação, negação, retomada ou sendo redita no texto de maneira diferente. Ela pode aparecer em uma relação de: sinonímia, como uma especificação, um desenvolvimento, generalização, totalização ou enumeração.

O que ocorre na reescritura por expansão é que o termo sobre o qual está sendo dito algo acaba sendo ampliado, o oposto do que é realizado quando a reescritura 
aparece por condensação, pois, nesse caso, a enunciação é condensada, ou seja, reduzida a uma forma menor. A reescritura pode aparecer por uma negação do enunciado anterior, ou com uma retomada do termo para que algo seja explicitado sobre ele. Por outro lado, a reescrituração de um termo pode aparecer substituída por outra expressão. Desse modo, seja qual for a forma em que a enunciação venha reescrita, é possível entendermos quais são os sentidos que ali estão sendo criados. Mas, para isso, precisamos, também, nos atentar às articulações que a expressão apresenta no texto.

Se com as reescrituras podemos observar as diversas formas como uma palavra vem reescrita no texto, com a articulação, o que conseguimos notar, são as relações entre as palavras e o processo no qual essas relações fazem algo significar. Ou seja, é na contiguidade das palavras que se dão os sentidos em um enunciado. De acordo Guimarães, as relações de articulação ocorrem de três maneiras diferentes, sendo elas: por dependência, por coordenação e por incidência.

Eduardo Guimarães explica que, na articulação por dependência, os elementos linguísticos estão organizados de tal forma que acabam se tornando um só. A menção de apenas um dos constituintes já é suficiente para retomar todo o enunciado. Por outro lado, na articulação por coordenação temos constituintes linguísticos de mesma natureza que, do modo como estão agrupados no enunciado, passam a constituir um só elemento. Por último, Guimarães apresenta a articulação por incidência, essa relação se dá entre componentes linguísticos de natureza distinta, que juntos formam um novo componente de natureza similar ao último deles.

Nos procedimentos de reescritura e articulação, podemos ter a ocorrência de uma enumeração dentro do texto. Guimarães explica que a enumeração reúne um conjunto de enunciados - ou uma adição ou agrupamento de palavras - e que juntos eles formam uma única unidade de sentido. Ainda em conformidade com o que Guimarães (2007, p.59) apresenta, a enumeração é “[...] Uma articulação coordenada que pode ser uma reescrituração que expande (ou condensa), um termo presente ou não, algo enunciado como "um todo"." Ou seja, a enumeração é uma articulação em que os seus constituintes se relacionam e fazem parte dos sentidos do enunciado, em que "o enumerado atribui sentido aos enumeradores".

\section{Domínio Semântico de Determinação (DSD)}

Importa dizer que, para essa corrente teórica, a relação com o exterior é construída linguisticamente. "A relação de uma expressão com as coisas [...] é relação de sentido entre palavras" (GUIMARÃES, 2007, p. 78), e as palavras significam de acordo com as relações de determinação semântica estabelecidas na enunciação. E analisar o sentido de uma palavra é constituir seu Domínio Semântico de Determinação (DSD), que busca explicar o funcionamento do sentido da palavra.

O DSD é a equivalência gráfica das relações de significação de enunciados dentro de um texto. É nele que estarão representadas as relações de determinante e determinado, entre as palavras, que implicam nos sentidos de um enunciado. Guimarães explica que a relação de determinação não é dada em relação à palavra quanto referenciadora de um objeto, pelo contrário, o autor explica que essa relação de sentidos é dada entre uma palavra e outra.

\section{Os Sentidos de Linguagem}

A escolha da Gramática do português contemporâneo de Cunha e Cintra se justifica pelo fato desse material ser muito utilizado para o ensino da gramática da 
língua portuguesa nas escolas brasileiras. Pela sua relevância no ensino, a Gramática do Português contemporâneo ainda hoje é utilizada para a elaboração de outros materiais didáticos. Sendo assim, nos atentamos a importância de se estudar a construção de sentidos da palavra "linguagem" nesse material, pois, a partir dessa compreensão é que podemos entender os sentidos e interpretações feitas com base nessa gramática.

A princípio, observamos todas as reescrituras da palavra "linguagem" no correr do texto, para que depois conseguíssemos determinar as articulações que foram feitas entre a palavra analisada, suas reescrituras e o restante do texto. Com isso, conseguiremos, ao final, apresentar os DSD's e os sentidos criados no texto. Para construir os DSD's, faremos uso dos sinais gráficos propostos por Guimarães: $\vdash$ (determina algo), $\dashv$ (está sendo determinado por algo), ----- (sinônimo) e (oposição).

A palavra "linguagem" aparece articulada por coordenação com os termos "Língua, discurso e estilo". Em seguida, temos uma reescritura de "linguagem" por repetição e outra por expansão e desenvolvimento, que estão determinando linguagem, como representado do DSD abaixo:

Quadro 1. DSD 1

\begin{tabular}{|lc|}
\hline $\begin{array}{l}\text { Processos psíquicos } \dashv \text { Linguagem } \vdash \text { Vida } \\
\text { social } \\
\end{array}$ & $\perp$ \\
Língua
\end{tabular}

Fonte: Elaboração própria.

O que podemos observar é que, como representado no DSD, dentro da reescritura por expansão e desenvolvimento, os termos "processos psíquicos" e "vida social" estão construindo o sentido de linguagem nesse texto específico. Ou seja, de acordo com essa primeira observação, a linguagem tem caráter psíquico e é produto da vida social, ao passo que, através dela, é que se dá a concretização de qualquer língua.

Ainda no primeiro parágrafo do texto, "linguagem” é reescrita por substituição pelo "O termo" e reescrita por definição com "[...] O sistema de sinais que serve de meio de comunicação entre os indivíduos [...]" (Cunha e Cintra, 1998, p. 1). Logo em seguida, há uma reescritura por repetição que se articula, por incidência, com "[...] Desde que se atribua valor convencional a determinado sinal [...]". Com essas observações podemos representar as relações de determinação da seguinte forma:

Quadro 2. DSD 2

$$
\begin{gathered}
\text { Sistema de sinais } \dashv \text { Linguagem } \vdash \text { Meio de } \\
\text { comunicação } \\
\text { Valor convencional }
\end{gathered}
$$

Fonte: Elaboração própria.

Ou seja, "Sistema de sinais", "valor convencional" e "Meio de comunicação", estão, nesse trecho, determinando os sentidos da palavra "linguagem", de forma a construir como "linguagem" é um sistema de sinais que tem valores atribuídos por convenção e que serve para a comunicação entre os indivíduos. Além do mais, no final do trecho, temos uma reescritura por repetição e determinação que se articula com uma 
reescritura de linguagem por especificação, em que linguagem aparece dividida como "linguagem falada" ou "articulada".

De acordo com Guimarães (2007, p.79), "[...] Não há relação de determinação sem que ela seja nas duas direções e construída na enunciação. [...]”. Sabendo disso, apresentaremos os DSD's das palavras "língua, discurso e dialeto" que, nessa gramática, acabam por construir os sentidos de "linguagem".

No segundo parágrafo do primeiro capítulo, encontramos uma reescritura por definição da palavra língua como mostra o seguinte trecho: "Língua é um sistema gramatical pertencente a um grupo de indivíduos". Já no fragmento "Expressão da consciência de uma coletividade, a LÍNGUA é o meio por que ela concebe o mundo que a cerca e sobre ele age", temos, inicialmente, em "expressão da consciência de uma coletividade", uma reescritura por expansão que produz um desenvolvimento; e, no último período, temos uma reescritura de língua por repetição e uma articulação.

Ainda no mesmo parágrafo, localizamos as seguintes reescrituras por elipse de língua: "utilização social da faculdade de linguagem", "criação da sociedade", "não pode ser imutável" e "tem de viver em perpétua evolução". Observamos que cada reescritura e articulação constituem o sentido de língua e com base nas análises construímos o seguinte DSD dessa palavra:

Quadro 3. DSD 3

Concepção de mundo
$T$
Sistema gramatical $\dashv$ Língua $\vdash$ Expressão da consciência
$T$
Coletividade da língua

Fonte: Elaboração própria.

O que podemos ver representado no DSD é que, "Sistema gramatical, Expressão da consciência e Coletividade da língua" estão determinando o sentido de Língua, enquanto Língua determina a concepção de mundo. Ainda nesse parágrafo, pudemos observar que a expressão "Faculdade da linguagem" aparece como uma reescritura por especificação do que Cunha e Cintra inicialmente definem como Linguagem. E, o que o texto apresenta, é uma articulação de língua com a faculdade da linguagem.

No parágrafo seguinte, temos discurso articulando-se com língua em "Discurso é a língua no acto, na execução individual", em que podemos apontar as expressões "língua no acto" e "execução individual" que estão construindo o sentido de discurso. Ainda nesse trecho, temos as expressões "ideal linguístico", "sistema idiomático" e escolhas de expressão que também influenciam no que entendemos por discurso na referida gramática. O que também é apresentado no corpo do texto é a palavra Língua, que acaba por determinar a expressão "Estilo". Ilustramos essas relações entre determinantes e determinados com o seguinte DSD: 
Quadro 4. DSD 4

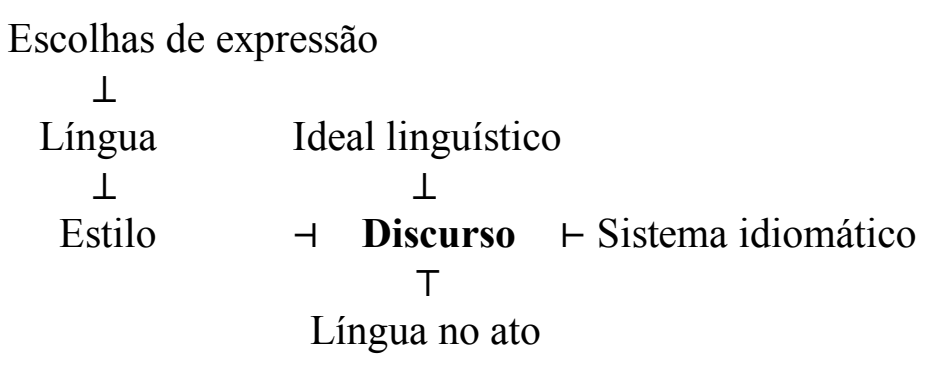

Fonte: Elaboração própria.

Mais adiante, encontramos uma reescritura por repetição de linguagem articulada com língua e discurso por coordenação, produzindo uma enumeração. Aqui, língua e discurso estão determinando o sentido de linguagem. Em seguida, as expressões "linguagem, língua e discurso" aparecem reescritas por condensação em "as três denominações" que, por sua vez, articula-se com "comunicação humana", cujo sentido é determinado por língua. Além disso, pudemos observar que a expressão "três denominações" está determinando o sentido de comunicação humana.

No segundo tópico da gramática, observamos na expressão "Língua e sociedade: variação e conservação linguística", uma articulação entre as palavras língua e sociedade, reforçando o caráter social que a língua tem e que os gramáticos defendem nesse livro. Em seguida, temos no fragmento “[...] VARIAÇÕES DIAFÁSICAS (língua falada, língua escrita, língua literária, linguagens especiais, linguagem dos homens, linguagem das mulheres, etc.)", observamos uma enumeração de reescrituras das palavras língua e linguagem. Cada reescritura articula-se a um termo que especifica e, portanto, traz novos significados à língua e à linguagem. Para a palavra língua temos: Língua $\vdash$ padrão, Língua $\vdash$ falada, Língua $\vdash$ escrita e Língua $\vdash$ literária. Enquanto que linguagem aparece articulada por dependência por: "linguagens especiais, linguagem dos homens e linguagem das mulheres".

Em seguida, o texto apresenta uma articulação de língua, explicada na enumeração, com os termos "competência linguística" e "variação". Ademais, a expressão "sistema da língua" também aparece articulada com o que os autores explicam por língua e se articula por especificação com a enumeração "[...] fonético, fonológico. morfológico, sintático etc. [...]" (CUNHA e CINTRA, 1998, p. 2). Cunha e Cintra (1998) retomam a enumeração com uma reescritura por condensação e substituição em que o termo "multiplicidade de realizações" condensa a enumeração que havia sido feita, articulando-a com uma reescritura por redução em que sistema da língua aparece como sistema. Para esse trecho, temos o seguinte DSD:

Quadro 5. DSD 5

\begin{tabular}{cc|}
\hline Língua $\dashv$ Sistema da língua $\_$sistema $\vdash$ variação \\
$\perp$ \\
realizações
\end{tabular}

Fonte: Elaboração própria.

Mais à frente, encontramos duas reescrituras por repetição de "linguagem". A primeira encontra-se na expressão "erro em linguagem" e constitui uma oposição com "falar correcto" que se articula com "o falar que a comunidade espera", enquanto "erro em linguagem" está articulada com "desvios desta norma". "falar correcto" e "erro em 
linguagem" estão, portanto, determinando o sentido de "linguagem". A segunda reescritura por repetição aparece em "valorização da linguagem", a qual se articula com "ideal linguístico". Podemos, então, representar essas relações de determinação com o DSD abaixo:

Quadro 6. DSD 6

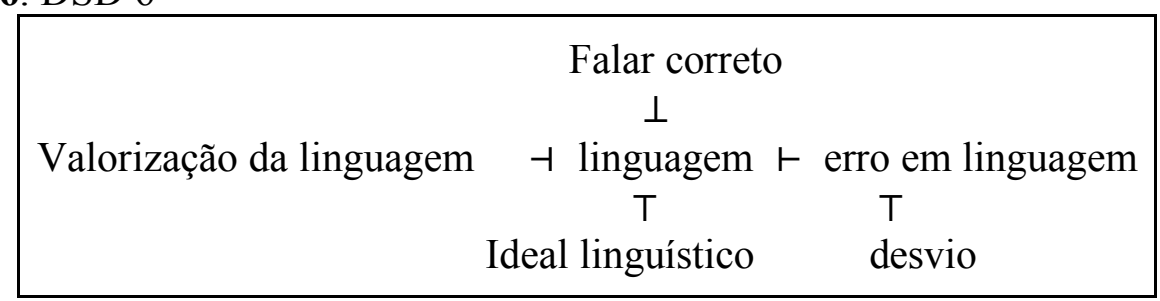

Fonte: Elaboração própria.

No terceiro tópico do primeiro capítulo da gramática temos, já no subtítulo, uma articulação entre "língua", "diversidade geográfica", "dialeto" e "falar". Ao que, no corpo do texto, dialeto é definido como uma forma regional da língua. Ao que os gramáticos dão continuidade apontado as diferenças entre o dialeto e o falar. Ilustramos esses apontamentos com o DSD:

Quadro 7. DSD 7

Fonte: Elaboração própria.

$$
\begin{aligned}
& \text { Peculiaridade expressiva } \\
& \perp \\
& \text { falar } \vdash \text { manifestações orais }
\end{aligned}
$$

sistema de sinais

$\perp$

regionalidade $\dashv$ Dialeto $\vdash$ língua

língua

Sobre esse DSD, podemos explicar que a palavra língua, ao mesmo tempo em que constrói os sentidos de "dialeto", também está sendo apresentada em uma relação de oposição. Já a fala, os autores explicam que falar não apresenta a mesma dimensão que um dialeto tem, pois falar conta apenas com "manifestações orais".

Ademais, já no segundo capítulo da gramática de Cunha e Cintra (1998), continuamos por buscar as reescrituras e articulações no texto. A princípio, logo no título do capítulo, encontramos uma reescritura de língua por "língua portuguesa", ou seja, nesse momento do texto, língua portuguesa para determinar o que é língua. Assim, temos uma reescritura por repetição da expressão "língua portuguesa", e, logo após, reescrito por redução, em que aparece apenas como "português" e articula-se com "língua viva" e "variedades". Nesse trecho, a palavra "português" acaba sendo determinada por "língua viva", logo, o que podemos dizer acerca disso é que, língua viva constrói os sentidos de português e por consequência, de língua.

A partir da analise que empreendemos, construímos o seguinte DSD final: 
Quadro 8. DSD 8

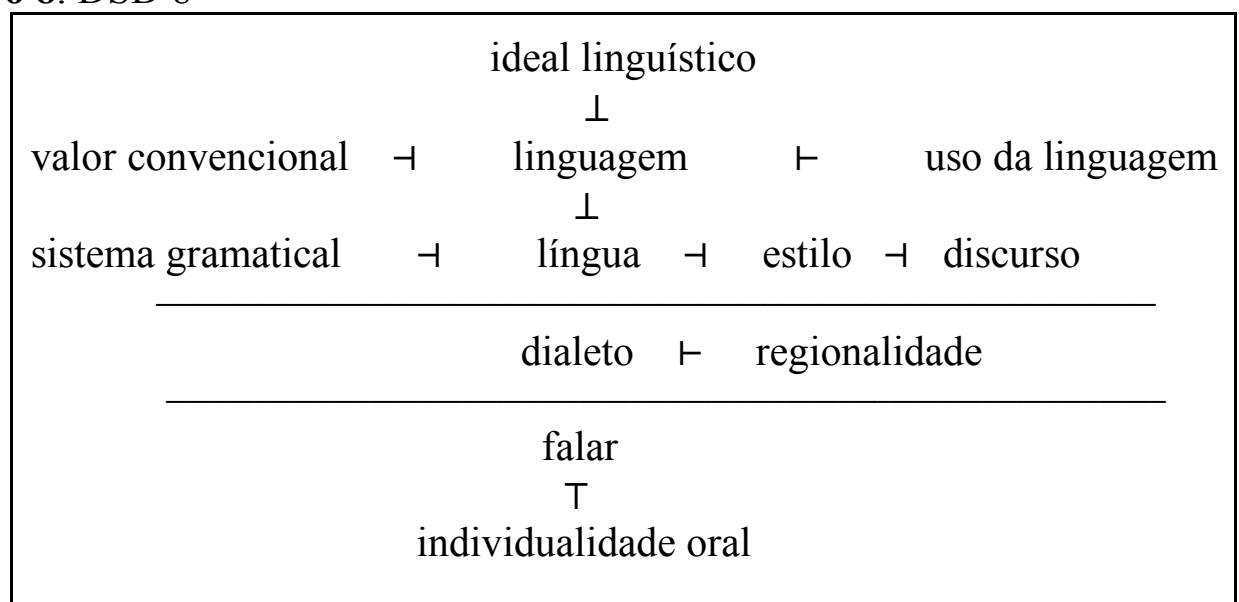

Fonte: Elaboração própria.

\section{Considerações finais}

Com a análise que apresentamos, podemos afirmar que língua, nesse texto, apresenta um sentido de sistema organizado de acordo com um a gramática, determinado por uma convenção social, cuja função maior é estabelecer (intermediar) a relação (interação) entre os indivíduos e o mundo. A língua é, nessa gramática, diferente do dialeto e da fala. Enquanto dialeto diz respeito às marcas regionais de uso da língua, falar corresponde às manifestações orais, às peculiaridades de expressão. Desse modo, a partir dos sentidos dessas palavras que compõem o DSD de "linguagem", podemos dizer que esta palavra possui, neste texto, os sentidos de uma espécie de conjunto abstrato de sinais que serve como meio de comunicação entre os indivíduos presentes em uma comunidade. Os valores de cada sinal são resultado de uma convenção social, esses valores convencionais estão construindo os sentidos de linguagem. Segundo o que os autores escreveram, a linguagem representa um ideal linguístico, e seu uso é passível de erros de linguagem.

\section{REFERÊNCIAS}

CUNHA, Celso; CINTRA, Lindley. Breve Gramática do Português Contemporâneo. 14. ed. Lisboa: Edições João Sá da Costa, 1998.

GUIMARÃES, Eduardo. Semântica do Acontecimento: um estudo enunciativo da designação. Campinas: Pontes, 2002.

GUIMARÃES, Eduardo. A ENUMERAÇÃO FUNCIONAMENTO ENUNCIATIVO E SENTIDO. Cadernos de Estudos Linguísticos, Campinas, v. 51, n. 1, p.49-68,2009.

MOLliCA, Maria Cecília; GUIMARÃES, Eduardo. "Domínio Semântico de Enunciação". In: A palavra: forma e sentido. Campinas: Pontes, RG Editores, 2007.

Recebido em: maio de 2018. Aprovado em: julho de 2018.

Como citar este trabalho:

REIS, R. O.; SOUZA, P. T. C. de; VENTURA, A. Os sentidos da palavra "linguagem" na Gramática do Português Contemporâneo de Celso Cunha e Lindley Cintra: uma análise enunciativa. Traços de linguagem, v. 2, n. 2, p. 20-28, 2018. 